\title{
Users' Experiences With Home Mechanical Ventilation: A Review of Qualitative Studies
}

\author{
Lisbeth Ørtenblad, Kathrine Carstensen, Ulla Væggemose, Claus Løvschall, Michael Sprehn, \\ Simone Küchen, Ole Nørregaard, and Lotte G Jensen
}

\begin{abstract}
BACKGROUND: Users of home mechanical ventilation encounter major psychological and physiologic challenges. To ensure well-functioning home mechanical ventilation, users' experiences of care and treatment are important knowledge to supplement clinical perspectives. This systematic review aimed to summarize current qualitative evidence regarding experiences of home mechanical ventilation users. METHODS: By following Preferred Reporting Items for Systematic Review and Meta-Analyses guidelines, 9 databases were systematically searched. Seven studies met the inclusion criteria after title and/or abstract screening and full-text assessment. These were appraised by using the Relevance, Appropriateness, Transparency, Soundness checklist. Thematic analysis guided data extraction and identification of the findings. The Confidence in the Evidence for Reviews of Qualitative Research tool was applied to assess the confidence of the findings. RESULTS: The review showed high confidence in $\mathbf{4}$ findings: an increase in quality of life, feeling forced to accept home mechanical ventilation, collaboration between home-care assistants and users of home mechanical ventilation is challenging, and information about the technology from a user's perspective. The review showed moderate confidence in 2 findings: living at home is pivotal for a normalized everyday life, and home mechanical ventilation causes a life with continued worries and uncertainty. CONCLUSIONS: According to the users, treatment by home mechanical ventilation resulted in increased well-being and facilitated a community- and home-based lifestyle compared with institutional-based treatment. However, the users also expressed difficulties in coming to terms with the necessary extensive surveillance, which gave rise to a sense of undermined autonomy and self-determinism as well as continued worries and uncertainty. The users called this situation dependent independency. As a result of the review we call for an increased focus on a patientcentered treatment and care. Key words: home mechanical ventilation; personal narratives as topics; patient participation; systematic review; grade approach/CERQual; qualitative research. [Respir Care 2019;64(9):1157-1168. @ 2019 Daedalus Enterprises]
\end{abstract}

\section{Introduction}

Home mechanical ventilation is an expensive and highly specialized treatment used by a small but growing group

\footnotetext{
Ms Ørtenblad, Ms Carstensen, Dr Væggemose, Mr Løvschall, and Dr Jensen are affiliated with DEFACTUM, Public Health and Health Services Research, Central Denmark Region, Aarhus, Denmark. Dr Sprehn is affiliated with Respiratory Center South, University Hospital, Odense, Denmark. Dr Küchen, Danish Respiratory Centre East, Rigshospitalet, Glostrup, Denmark. Dr Nørregaard is affiliated with the Department of Anaesthesiology and Intensive Care, Aarhus University Hospital, Aarhus, Denmark.
}

of patients. ${ }^{1-4}$ Being dependent on day and night ventilator support, including continuous surveillance (caregivers watching over) and comprehensive health care, users of

\footnotetext{
The study was performed at DEFACTUM, Public Health and Health Services Research, Central Denmark Region, Aarhus N, Denmark.

The authors have disclosed no conflicts of interest.

Correspondence: Lisbeth Ørtenblad MA MPH, Public Health and Health Services Research, Central Denmark Region, Olof Palmes Alle 15, 8200 Aarhus N, Denmark. E-mail: Lisbeth.Oertenblad@stab.rm.dk.
}

DOI: $10.4187 /$ respcare. 06855 


\section{Users' Experiences With Home Mechanical Ventilation}

home mechanical ventilation are among the most vulnerable individuals with chronic illness. ${ }^{1,5}$ Respiratory insufficiency may result from weakness in ventilatory muscles, disturbances in the nervous system's transmission of signals, or changes in the lungs. ${ }^{5,6}$ In addition, home mechanical ventilation users often have other physical and chronic disabilities related to their disease..$^{7,8}$

Ventilation needs of users of home mechanical ventilation are supported in various ways but typically by invasive (tracheostomy) or noninvasive (mask) treatment.9,10 Home mechanical ventilation was introduced in the early 1950s to patients with late sequelae after polio as an alternative to hospitalization. This initiated a new treatment paradigm, which has spread to other disease groups. ${ }^{5}$ Today, users of home mechanical ventilation constitute a heterogeneous group with many different diagnoses; the most common diagnoses include patients with different neuromuscular disorders (including amyotrophic lateral sclerosis, tetraplegia, brain injury, and muscular dystrophy). The European Commission identified $\sim 22,000$ patients who were ventilator dependent in 16 European countries, with an estimated prevalence of 6.6 per 100,000 persons. ${ }^{11}$ Results of recent studies indicate an increase in the use of home mechanical ventilation in Denmark, with a 25\% increase between 2012 and 2016, ${ }^{12}$ and, in Canada, with a $278 \%$ increase from 2000 to $2012 .^{2}$ The main reason for the considerable increase in ventilation treatment among users who require surveillance and health-care support is that access is greater than dropout (death, recovering, rejection of home mechanical ventilation). Also, an awareness of which disease groups can benefit from the treatment as well as the effect of and experience with new technology might influence the increase. . $^{2,11,12}$

Home mechanical ventilation permits a more normal everyday life than that permitted by the former institutionalized and hospital-based ventilation treatment. Nevertheless, home mechanical ventilation represents a difficult life situation, which involves major psychological, physiologic, social, and existential challenges. Because users of home mechanical ventilation are dependent on health-care support for up to $24 \mathrm{~h}$ a day, services must accommodate not only treatment but also personal needs. However, results of studies indicate that attitudes to care and treatment may differ between health professionals and users of home mechanical ventilation. ${ }^{13-15}$ Lofaso et al ${ }^{13}$ identify differences between users of home mechanical ventilation and health professionals' perceptions of well-functioning home mechanical ventilation treatment. Other studies found disparities in the assessments of users of home mechanical ventilation health conditions, which meant that users may experience their health as good, whereas health-care professionals conclude the opposite. ${ }^{14,15}$ Thus, to ensure wellfunctioning home mechanical ventilation, it is important that users' experiences of care and treatment are integrated
Table 1. Definition of the Components of the Study

\begin{tabular}{|c|c|}
\hline Term & Definition \\
\hline Population & $\begin{array}{l}\text { Adults suffering from chronic } \\
\text { respiration/chronic respiratory } \\
\text { failure and receiving home } \\
\text { mechanical ventilation }\end{array}$ \\
\hline $\begin{array}{l}\text { Phenomenon of interest (substitute } \\
\text { the standard component } \\
\text { 'Intervention' of the PICO } \\
\text { model. Likewise, the standard } \\
\text { component 'Outcome' is part of } \\
\text { Phenomenon of interest) }\end{array}$ & $\begin{array}{l}\text { Subject perspectives of home } \\
\text { mechanical ventilation }\end{array}$ \\
\hline Context & $\begin{array}{l}\text { Home mechanical ventilation with } \\
\text { surveillance } 24 \text { h or most of the } \\
\text { day and night; English speaking } \\
\text { or European countries }\end{array}$ \\
\hline
\end{tabular}

$\mathrm{PICO}=$ population, intervention, comparison, outcome

into the biomedically based perspectives. The aim of this study was to present the current qualitative evidence regarding the experiences of users of home mechanical ventilation with home mechanical ventilation delimited to users dependent on surveillance and health-care support almost $24 \mathrm{~h}$ a day. Analytically, the Confidence in the Evidence for Reviews of Qualitative Research (CERQual) approach was applied.

\section{Methods}

\section{Search Strategy}

The review was conducted according to the Preferred Reporting Items for Systematic Review and Meta-Analyses (PRISMA) guidelines. A systematic literature search and selection strategy was formulated based on a Population, Intervention, Comparison, Outcome (PICO) model adapted to fit qualitative literature reviews (Table 1). Search terms were formulated accordingly, by typically using Medical Subject Heading terms. The formulation of search terms and the literature search were conducted with the assistance of an experienced research librarian. The terms were tested in preliminary searches to ensure that relevant studies were identified. The literature search was performed in January 2017 and updated in November 2017. Nine databases were searched (MEDLINE, Embase, Cinahl, Cochrane Library, PsychINFO, JSTOR, Social Services Abstracts, Sociological Abstracts, and Web of Science). The search was limited to studies written in English or Scandinavian languages and published in peer-reviewed journals during the period 2007-2017. This time limit was chosen due to the significant development of home mechanical ventilation technology; ventilators are now smaller and more advanced, which means that previous patient experiences may differ substantially from current patient experiences with home mechanical ventilation. 


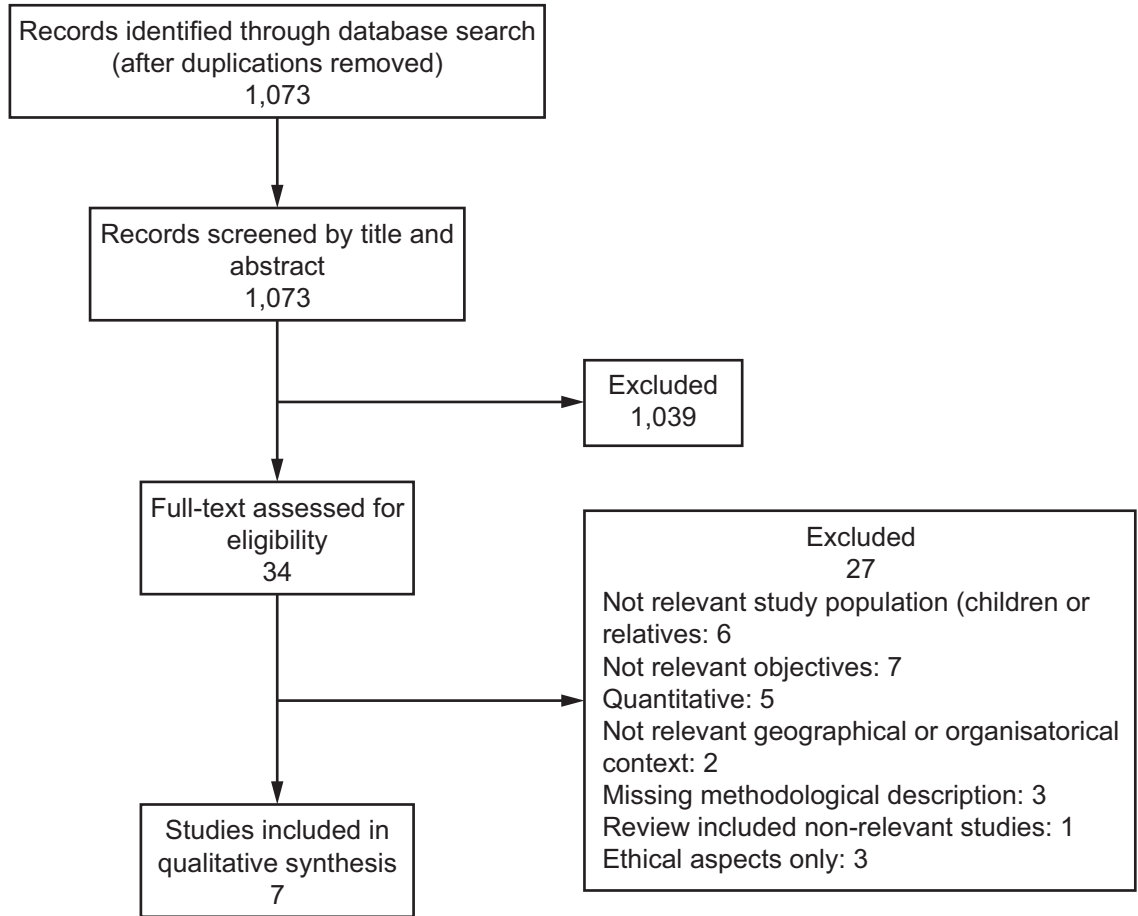

Fig. 1. Flow chart.

\section{Inclusion and Exclusion Criteria}

Qualitative and mixed-method studies and reviews that focused on criteria encompassed in the PICO model (Table 1) were included. Studies that included non-relevant patient groups, such as patients with sleeping disorders, obesity-related hypoventilation, tuberculosis, chronic obstructive pulmonary disease, were excluded because they are usually not dependent on surveillance and health-care support most of the day. Weaning studies and home discharge studies were also excluded.

\section{Study Selection}

The systematic search identified 1,073 candidate publications after removal of duplicates. These publications were screened for eligibility by title and abstract according to the inclusion and exclusion criteria. This was done independently by two of us (L Ø, LGJ). Thirty-four publications were identified for full-text assessment, which was performed independently by two of us (LØ, LGJ). Any disagreements were resolved by consensus. A manual search of reference lists identified no additional publications. Consequently, a total of 7 studies were included in the review (Fig. 1). 1,14,15,19-22

\section{Quality Assessment}

The Relevance, Appropriateness, Transparency, Soundness checklist for qualitative studies was used to assess the methodological quality. The quality assessment of each study was performed independently by two of us (LØ, LGJ) and afterward discussed between us. Finally, an overall assessment of minor, moderate, or substantial methodological limitations was assigned to each study (Table 2).

\section{Data Extraction and Synthesis}

Thematic synthesis was used for identification and synthesis of review findings across the included studies. ${ }^{16}$ The studies were read by 3 of us (L $\varnothing$, LGJ, KC) independently, with the aim of inductively generating codes that included the findings. These codes were discussed in depth by us, and any disagreements were solved by consensus. A test coding was performed by 3 of us (LØ, LGJ, KC), which resulted in minor revisions of definitions of the codes, and 6 codes were chosen: (1) increase in quality of life, (2) living at home is an important option, (3) feeling forced to accept home mechanical ventilation, (4) a life with worries and uncertainty, (5) collaboration between home-care assistants and users of home mechanical ventilation is challenging, and (6) information about the technology from a user perspective. All included studies were then coded by using Nvivo 11 software. The analyses of the findings were performed by all the authors. In the presentation of the findings citations from the included studies were used to illustrate key issues of the findings. These citations were selected to present general points of findings across the studies. 


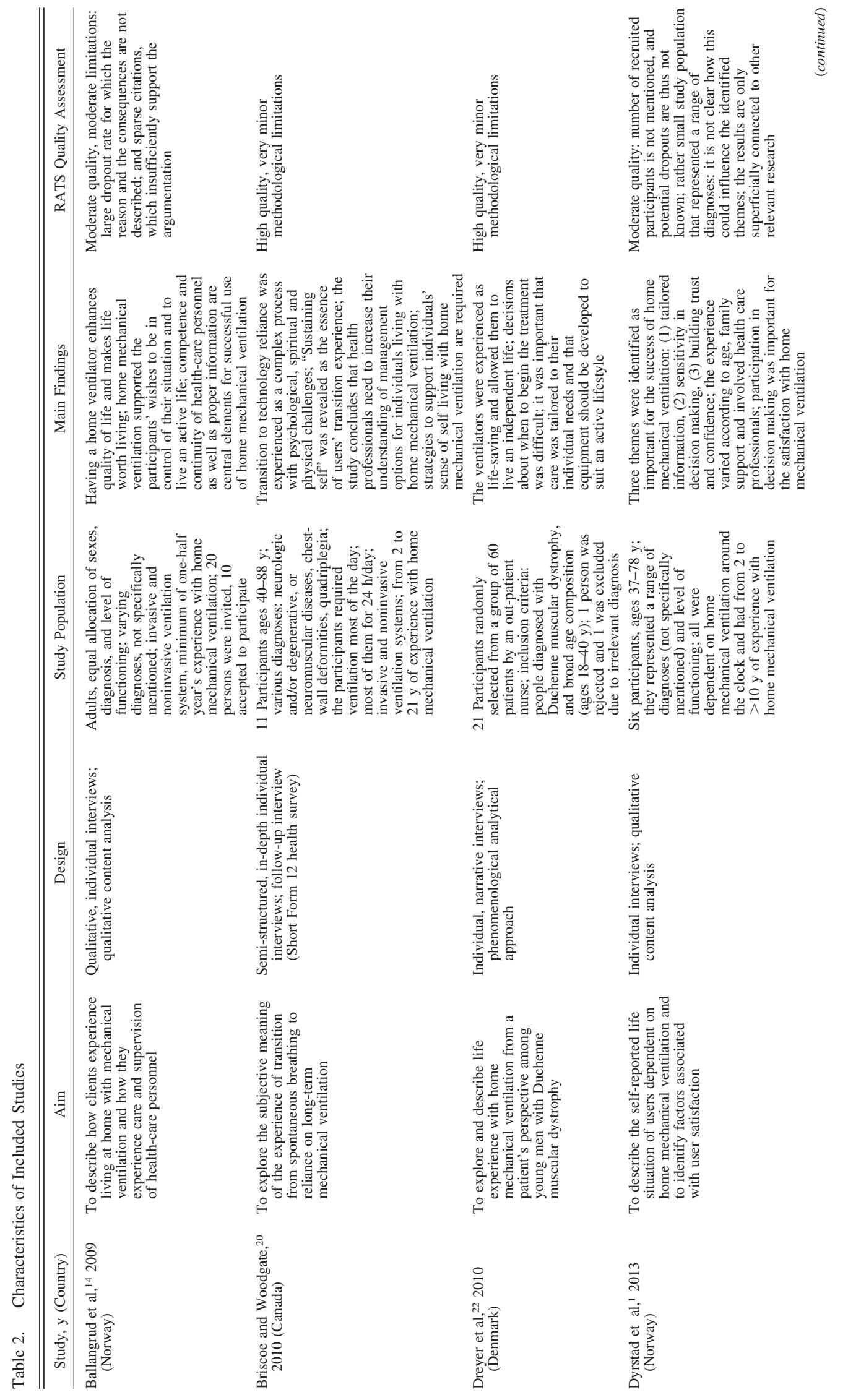




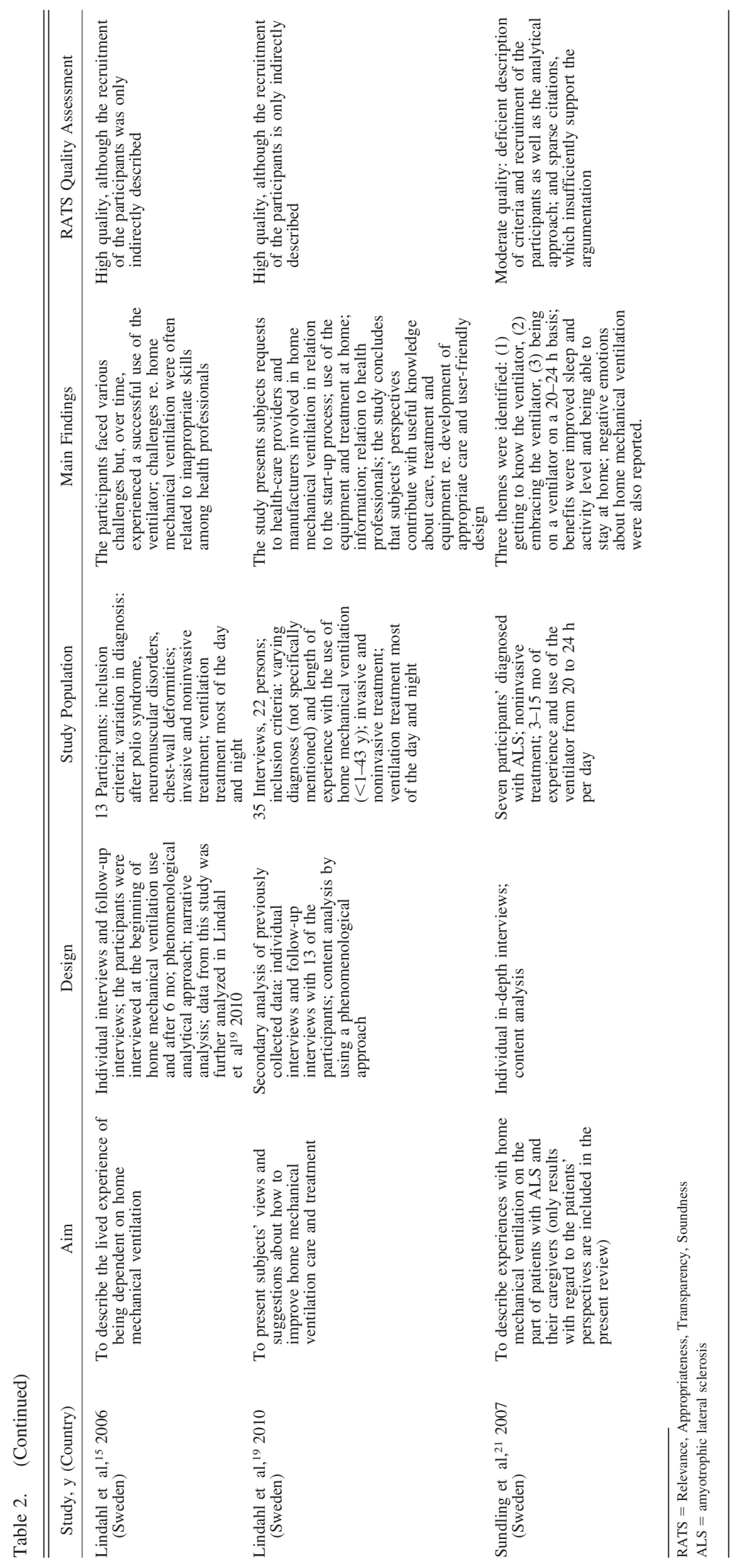




\section{Assessment of Confidence in the Review Findings}

The CERQual approach was applied to estimate confidence in the review findings. ${ }^{17,18}$ CERQual offers an assessment of the evidence, which supports a qualitative review finding. It is based on the assessment of 4 key components: methodological limitations (based on the Relevance, Appropriateness, Transparency, Soundness tool), relevance, coherence, and adequacy of the data. Assessment of these 4 components for each review finding allowed for an estimation of the overall confidence, judged as high, moderate, low, or very low confidence in the finding. "High confidence" referred to a review finding that was highly likely to be a reasonable representation of the phenomenon of interest, whereas "very low confidence" referred to a review finding in which it was unclear if the finding was a reasonable representation. ${ }^{17,18}$ The review findings and the CERQual assessment of these are presented in Table 3.

\section{Results}

Of the 7 studies included, 1 was conducted in Canada, ${ }^{20}$ 1 in Denmark, ${ }^{22} 2$ in Norway, ${ }^{1,14}$ and 3 in Sweden. ${ }^{15,19,21}$ The studies differed in aim and focus, but all investigated users' perspectives were regarding experiences with home mechanical ventilation. In terms of methodology, all the studies used individual interviews. They applied different analytical approaches (Table 2). Two of the Swedish studies ${ }^{15,19}$ originated from the same project. Nevertheless, these studies were treated as individual study contributions because they addressed different aspects of the data material, and the study population of the 2 articles was not entirely overlapping (referring to the components "relevance" and "adequacy" of the CERQual assessment).15,19

The studies included a total of 100 subjects, ages 18$88 \mathrm{y}$, with chronic respiratory insufficiency who received invasive or noninvasive respiratory treatment at home with surveillance for most of the day. Two of the studies included subjects with Duchenne muscular dystrophy 22 and amyotrophic lateral sclerosis, ${ }^{21}$ respectively, and the remaining 5 studies $1,14,15,19,20$ included a variety of diagnoses; the most common of them were spinal disorders, brain injuries, muscular dystrophies and amyotrophic lateral sclerosis. In the presentation of the results, these studies did not distinguish between the various types of diagnosis or type of treatment (invasive or noninvasive). The users of home mechanical ventilation had from 6 months to $21 \mathrm{y}$ of experience with the treatment. The 6 findings of this systematic review are presented below.

\section{Increase in Quality of Life}

Six of the seven included studies ${ }^{14,15,19-22}$ described changes in quality of life for users of home mechanical ventilation. All the studies found that home mechanical ventilation resulted in an increase in the users' quality of life. This applied both to the users' physical condition (eg, they reported better sleep, fewer headaches, more energy, less fatigue) and to their psychological condition (eg, they reported a sense of renewed identity and also regained autonomy and self-determinism). The changes in wellbeing and health provided a feeling of rejoining life. The changes experienced were radical compared with their life before home mechanical ventilation, which was characterized by many restrictions, feelings of anger, and fear of death, whereas home mechanical ventilation entailed an experience of a healthier life and feeling more secure; for example, one of the subjects said, "much, much easier and much safer [with the ventilator]." 22 Some subjects expressed a life-saving experience, "it [the ventilator] saved my life and gave me much more quality." 22

Three studies ${ }^{19-21}$ also described that the use of home mechanical ventilation involved conflicting and paradoxical experiences. Along with the generally better physical health, the users found themselves constrained by new restrictions imposed by home mechanical ventilation, (eg, being physically connected to the ventilator and being dependent on assistance). In that sense, they felt they had to struggle for their self-determination and autonomy.

\section{Living at Home Is an Important Option}

Five of the included studies addressed the feelings connected to receiving home mechanical ventilation and care at home instead of being in an institution. ${ }^{1,14,15,19,20} \mathrm{Al}-$ though most of the subjects included in the studies had never lived in an institution, they expressed the importance of being able to live at home while receiving mechanical ventilation. Treatment at home, instead of in an institution, was thus valued by many of the subjects. They emphasized it as pivotal to be able to live an independent life, and, in addition, it contributed to a sense of exercising control. Treatment at home helped to normalize the subjects' everyday lives and enabled them to carry on with many of the activities they had been engaged in previously. 1,14,15,19,20 One study found that the subjects who lived at home expressed better quality of life than the subjects who lived in an institution. ${ }^{1}$ One of the subjects expressed the benefits of home treatment this way, "I'm definitely happier at home. I've got my own surroundings. I've got, you know, we've had to make adaptations to the house and stuff but I'm here. I've got my own neighborhood. I've got my pets. It's just a far better quality of life than I think you'd have in the hospital." ${ }^{20}$ However, home mechanical ventilation also transformed the home into a more hospital-like environment, ${ }^{15,19}$ although the users tried their best to minimize this transformation. 


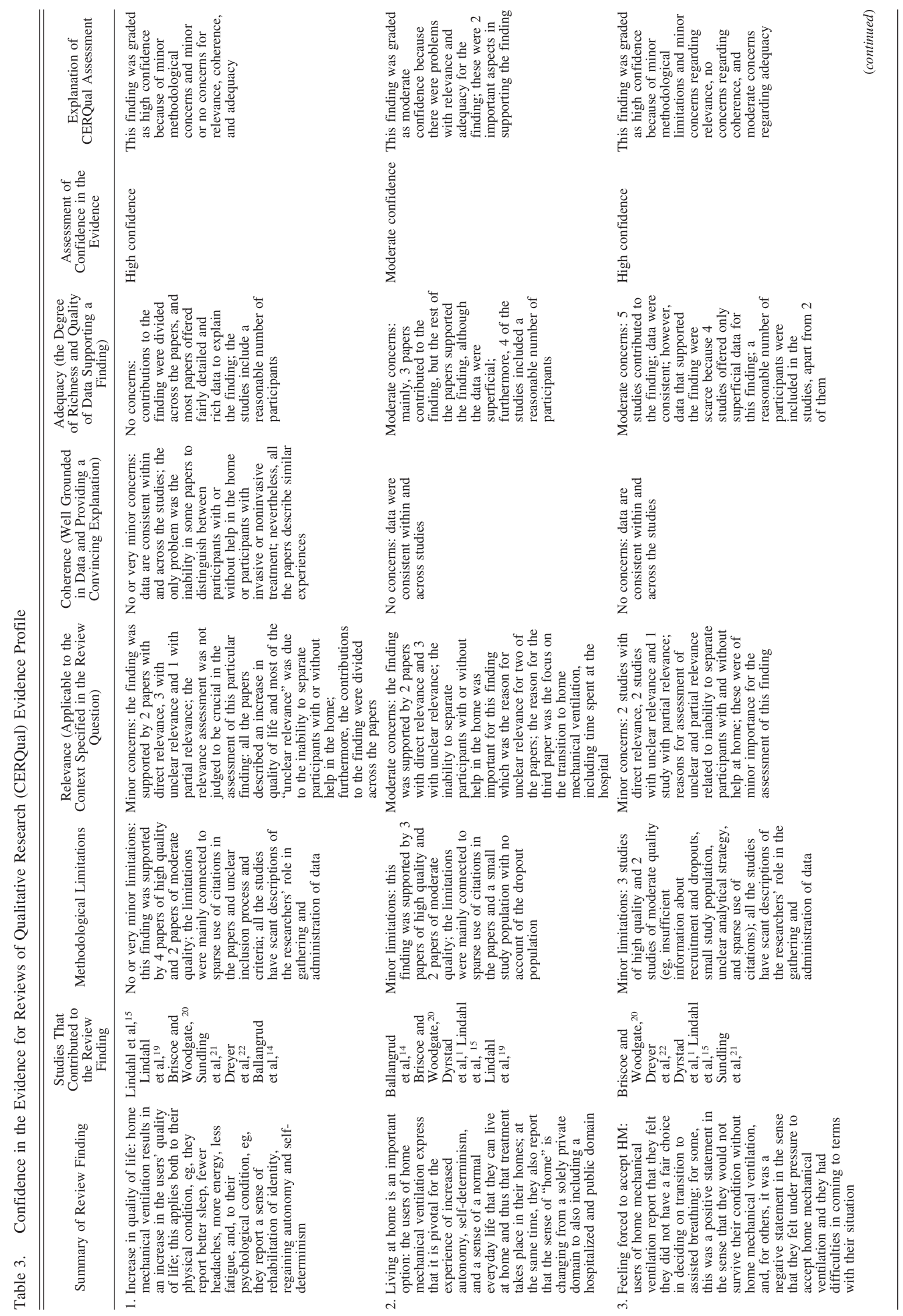




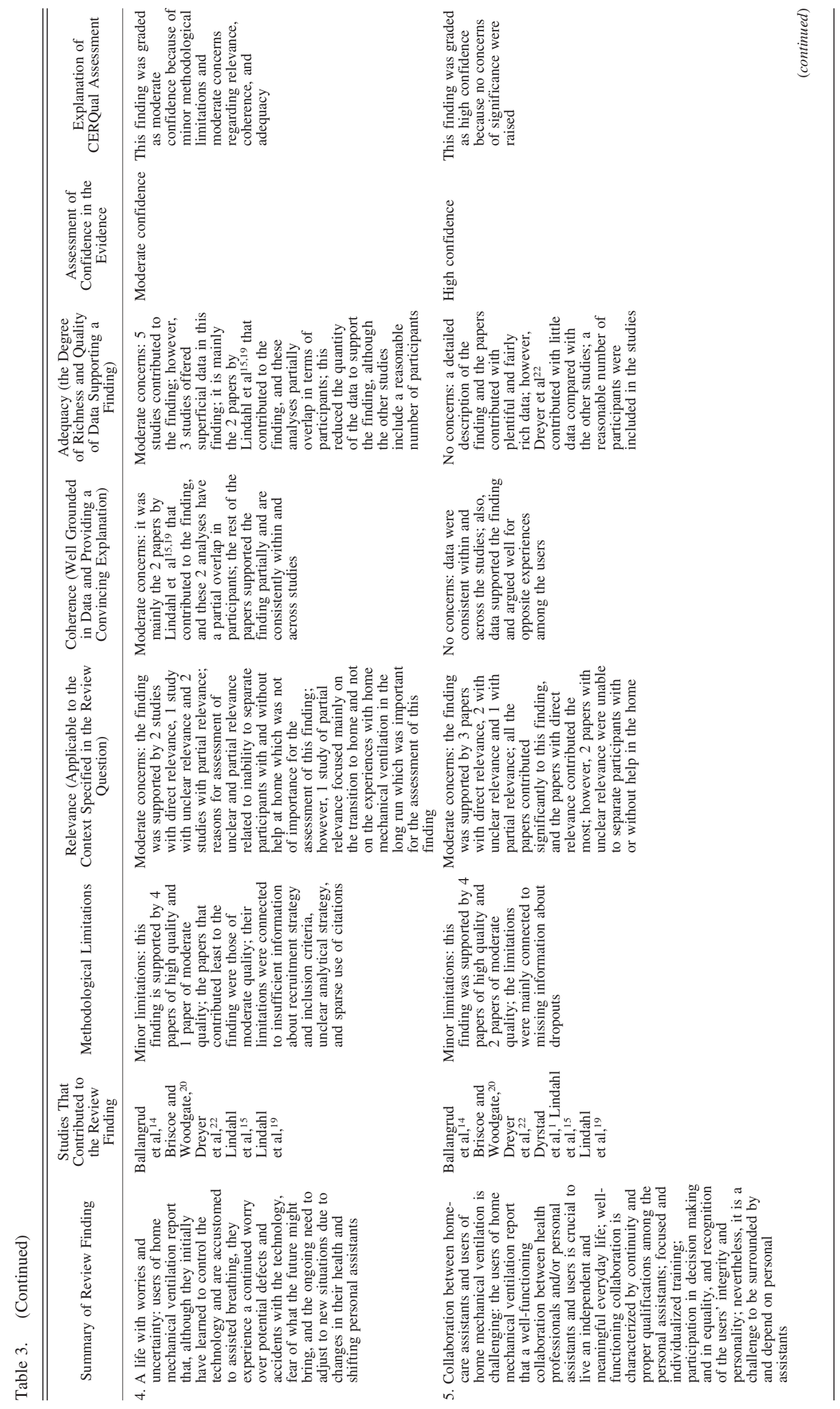




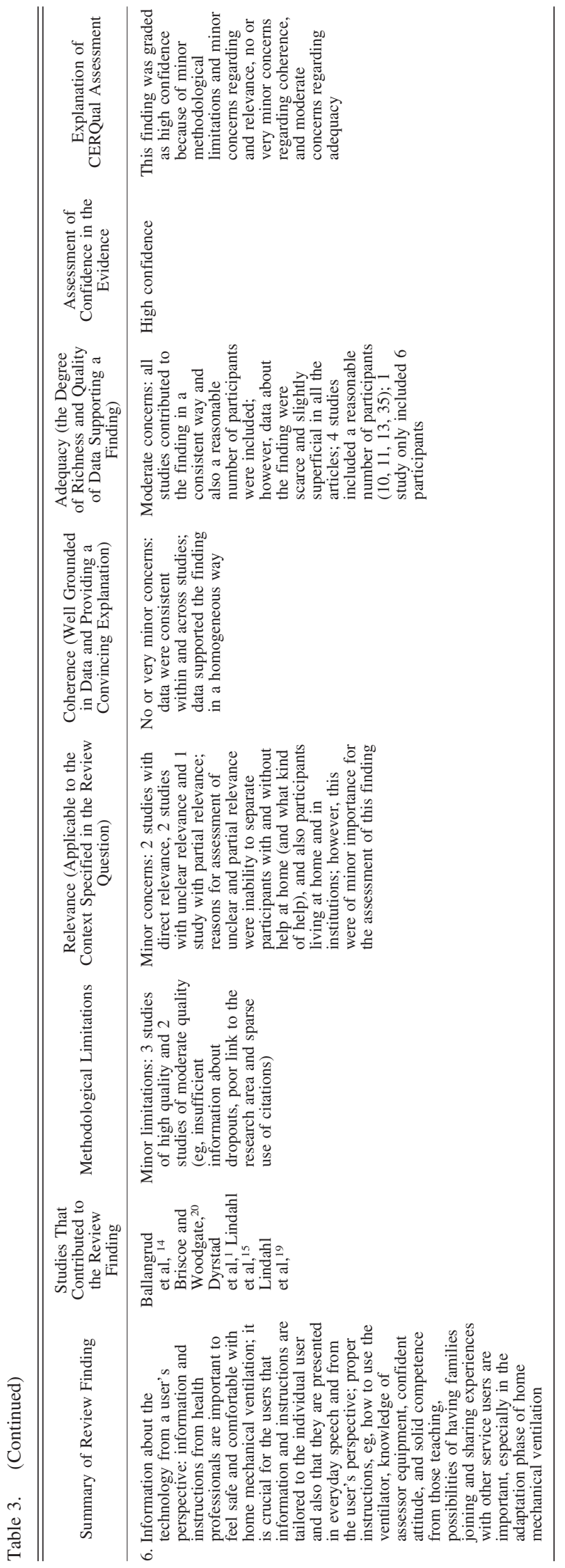

\section{Feeling Forced to Accept Home Mechanical Ventilation}

In 5 studies, ${ }^{1,19-22}$ the subjects reported that they felt forced to accept home mechanical ventilation, which meant that they felt that they did not have a fair choice in deciding on transition to assisted breathing. In some studies, the feeling of being forced to accept home mechanical ventilation was a positive statement that meant that the subjects had only 2 options, home mechanical ventilation or death, and no subjects wished to die. ${ }^{19,20,22}$ This theme was expressed in the following example: "because I want to live a little bit longer. I did not think there was anything to decide. It was not a real decision to make; it was necessary." 22

In other studies ${ }^{1,21}$ feeling forced to accept home mechanical ventilation was a negative statement. In these situations, the subjects expressed that they felt pressure to accept home mechanical ventilation, particularly from relatives, but occasionally also from health professionals who believed home mechanical ventilation would be beneficial. The subjects experienced this as an indirect or implicit pressure, but still, they indicated to feeling under a strain or a burden if they rejected the treatment. These subjects had difficulties in coming to terms with their situation and they also had a feeling of being trapped by the ventilator treatment. ${ }^{19}$ Some subjects reported having delayed the transition to home mechanical ventilation, which caused the start of treatment to be an acute life-saving action because of a potentially life-threatening situation. ${ }^{21,22}$

\section{A Life With Worries and Uncertainty}

In 5 studies, it was described that being dependent on home mechanical ventilation was associated with continual worries and uncertainty. ${ }^{14,15,19,20,22}$ Although the subjects appreciated the technology and the life it made possible, they also expressed a great deal of anxiety and insecurity. The subjects expressed that they feared the future and that the progression of their illness made the future uncertain and worrying. ${ }^{15,20}$ Furthermore, they were concerned about technological breakdowns and incorrect handling of the technology, as expressed by one of the subjects, "I am afraid that something is going to happen with the machine that I am unable to control or that the personnel cannot deal with." 19

Also, being dependent on others induced worries and uncertainty. ${ }^{14,15,19,22}$ In continuation hereof, the users stressed the importance of safety and security. ${ }^{14,15,19,22}$ To be able to trust in the expertise of the personal assistants, the professionals, and the relatives was a critical element in feeling safe. 


\section{Collaboration Between Home-Care Assistants and Users Is Challenging}

In 6 studies, the subjects reported on their collaboration with personal assistants at home, whether these were health professionals (mostly nurses or social and health-care assistants) or unskilled assistants.1,14,15,19,20,22 A precondition for a well-functioning collaboration between the homecare assistants and users of home mechanical ventilation was continuity and competence among these personal assistants. The users conveyed that having few and reliable people who were competent in the tasks of maintaining the technical equipment and also being sensitive toward individual needs increased their feelings of trust and safety. ${ }^{1,14,15,19}$ Also, it meant fewer education sessions.

Again, the users experienced a paradox because, simultaneously, they acknowledged the presence of the homecare assistants as a prerequisite for an independent life at home, while finding it hard and challenging to have people around all the time. They felt it undermined their autonomy and their sense of freedom. ${ }^{1,14,19,20}$ The users of home mechanical ventilation emphasized that participation in decision making about treatment, care, and how to organize daily living was pivotal for their sense of control in everyday life. ${ }^{1,14,20,22}$ A subject who used to have a job that involved managing big budgets expressed his decision capabilities this way, "I can make that judgment myself. Normally I play with a budget of a million; I really can manage to buy a bed!" 19 Furthermore, it was perceived as important that the home care was adapted to individual preferences. ${ }^{1,14,19,22}$

\section{Information About the Technology From a User's Perspective}

Information described in this section is defined as general information about the technology from the user's perspective, not just from home-care assistants. In 5 studies, the users of home mechanical ventilation emphasized the importance of having clear and sufficient information and instructions on the treatment, both for decision making and to feel safe and comfortable while living with the ventilator. ${ }^{1,14,15,19,20}$ In one of the studies, ${ }^{1}$ the users reported it to be crucial that information and instructions were tailored to the individual needs. They also found it important that instructions were presented to them in everyday language. However, they felt that this was not always the case. ${ }^{1}$

The internet is mentioned as an essential additional source of information. Sharing knowledge and experiences was valued, and provided the users with helpful advice about living with a ventilator. ${ }^{14}$ The users stated that appropriate information was particularly important in the initial phase of home mechanical ventilation to feel secure and positive about the treatment. Important information could include crucial material on ventilator use and knowledge of other technical equipment. In this initial phase, the subjects appreciated a confident attitude and solid competence from those teaching as well as the possibility of relatives joining. ${ }^{14,19,20}$

\section{Discussion}

Based on a systematic search, selection, and assessment of relevant literature, this review provided a synthesis of users' experiences with home mechanical ventilation. We applied the CERQual approach to grade the level of confidence in the review findings. Accordingly, we suggested high confidence in 4 of the findings: (1) home mechanical ventilation results in an increase in the users' quality of life, both physically and psychologically; (2) some patients experience feeling forced to accept the transition to home mechanical ventilation; (3) collaboration between home-care assistants and users of home mechanical ventilation is necessary but challenging, and requires continuity, competence, and sensitivity toward individual user preferences; and, finally, (4) proper and tailored information about home mechanical ventilation, especially in the initial phase, is important to feel safe and comfortable with home mechanical ventilation. We suggested moderate confidence in two of the findings: (1) living and being treated at home is important for a sense of a normalized everyday life, and (2) despite enabling life, home mechanical ventilation also caused continual worries and uncertainty among the users.

Overall, the review findings emphasized that home mechanical ventilation resulted in an increase in the users' quality of life, physically as well as psychologically. Moreover, home mechanical ventilation facilitated a more normal, community-based lifestyle than the users imagine institutional-based treatment and care would provide. However, the review also demonstrated that users of home mechanical ventilation experienced a paradox: on the one hand, appreciating the increase in quality of life that home mechanical ventilation enables and, on the other hand, experiencing continuing difficulties in coming to terms with their situation.

Interestingly, a recent study on oxygen therapy in general mentions the treatment as "a wolf in sheep's clothing." 23 The study showed that subjects experienced oxygen therapy as a burden together with its advantages, which indicated feelings of resentment, dependency, invasion of privacy, and being trapped due to the technology. Although the populations in this study and in our review comprised different diagnoses, the experienced consequences of ventilation treatment were similar. Our review also demonstrated a broad range in the users' experiences of home 
mechanical ventilation, from a major increase in quality of life and appreciation of normalizing their everyday life to sustained difficulties in coming to terms with home mechanical ventilation. The users phrase this paradox as "a dependent independency," which indicated that the essential personal assistants involved also challenge autonomy, that the technology was vital but also induced a sense of being trapped and undermined self-determinism, that the privacy of the home became institutionalized, and that the appreciation of home mechanical ventilation was experienced alongside continued fearfulness and worries.

As noted by Nakarada-Kordic et al, ${ }^{24}$ steps to accommodate such paradoxes should include providing proper information and counseling, and formulating patient-specific treatment and care initiatives. Similarly, this review demonstrated that the patients call for individualized and patient-specific counseling and communication plans as key points with regard to appropriate decision making, which indicated this to be a precondition to feel safe and confident with home mechanical ventilation. This was in line with another study that indicated that vulnerable groups of patients who were dependent on comprehensive healthcare support, benefit from being offered health-care services that are patient centered. ${ }^{25}$ Thus, there seemed to be a profound need for increased focus on patient involvement and co-operation.

Finally, an important aspect of the phrase "dependent independency" was that, although home mechanical ventilation is a necessity for surviving, some users, nevertheless, felt forced to accept the technology, for example, they felt under pressure, as one of the review findings showed. As noted by Ando et al, ${ }^{26}$ some patients reject home mechanical ventilation, stating that it is a threat to their identity and self-autonomy or arguing that home mechanical ventilation is not a satisfactory solution to their problems. Such statements were recognized in some of the challenges expressed by the users included in this review. However, knowledge on the rejection of home mechanical ventilation is limited, and we suggest this to be an important topic for future research.

\section{Limitations and Strengths of the Review}

A methodological limitation of this review was that variation among diagnoses, for example, mainly stationary disabilities (eg, tetraplegia) and fast-progressing conditions (eg, amyotrophic lateral sclerosis), may have an impact on patients' experiences with home mechanical ventilation, which the studies do not take into account. Nevertheless, to differentiate among diagnoses when planning studies might be difficult because users of home mechanical ventilation include only a small number of patients. Furthermore, the geographic context of the studies was mainly limited to Scandinavian countries, which raised questions about the generalizability of the findings. Differences among countries with regard to organizing and allocating support and surveillance may have impacted experiences among the users. Because the Scandinavian countries are rather similar in providing beneficial organizational frameworks for issues such as patient-centered care, the experienced challenges were likely to be even more present in other countries. Finally, the review encompassed only a few studies. The inclusion of quantitative studies, for example, surveys that focused on quality of life or burden related to home mechanical ventilation, might have added valuable insight.

Nevertheless, the methodological approaches to this review increased the reliability and credibility of the findings. The review was based on a systematic literature search and selection process according to PRISMA guidelines $^{27}$ and PICO. All the procedures were conducted by at least two of us, and, to optimize the validity of the review, any disagreement was discussed among the research team until consensus was attained. Also, well-established methods were used for synthesizing the studies included in this review. Use of the CERQual approach provided the possibility to systematically present qualitative research findings across studies as well as to assess the scientific confidence in these findings. Thus, this approach had enhanced the transparency and reliability of the review findings, which improved the trustworthiness of the results.

\section{Conclusions}

Based on the results of this qualitative review, it can be concluded that home mechanical ventilation led to an increase in the users' quality of life, both physically and psychologically. Furthermore, home mechanical ventilation facilitated a more normal, community-based lifestyle than the users imagined institutional-based treatment and care would provide. However, in addition, the results showed that home mechanical ventilation also caused continuous worries and uncertainty among users and that they experienced difficulties in coming to terms with the necessary extensive surveillance. Overall, although users of home mechanical ventilation appreciated the increased quality of life and the possibilities of living a life on individual terms and conditions that home mechanical ventilation enables, it also gave rise to a sense of undermined autonomy and self-determinism. The users called this situation "dependent independency," which meant that the dependence on the technology and the surveillance it required was a precondition for living an individual and independent life. To accommodate this paradox, the results of the review calls for an increased focus on user involvement and patient-centered treatment and care. Furthermore, when 


\section{Users’ ExPeriences With Home Mechanical Ventilation}

taking the experienced paradox into consideration, future research may include perspectives of users who reject home mechanical ventilation to qualify decision making regarding the use of the treatment.

\section{REFERENCES}

1. Dyrstad DN, Hansen BS, Gundersen EM. Factors that influence user satisfaction: tracheotomised home mechanical ventilation users' experiences. J Clin Nurs 2013;22(3-4):331-338.

2. Povitz M, Rose L, Shariff SZ, Leonard S, Welk B, Jenkyn KB, et al. Home mechanical ventilation: a 12-year population-based retrospective cohort study. Respir Care 2018;63(4):380-387.

3. Laub M, Berg S, Midgren B. Home mechanical ventilation in Sweden-inequalities within a homogenous health care system. Respir Med 2004;98(1):38-42.

4. Chu CM, Yu WC, Tam CM, Lam CW, Hui DS, Lai CK; Hong Kong Home Ventilation Registry, Hong Kong Thoracic Society. Home mechanical ventilation in Hong Kong. Eur Respir J 2004; 23(1):136-141.

5. Bach JR, Rajaraman R, Ballanger F, Tzeng AC, Ishikawa Y, Kulessa R, Bansal T. Neuromuscular ventilatory insufficiency: effect of home mechanical ventilator use vs. oxygen therapy on pneumonia and hospitalization rates. Am J Phys Med Rehabil 1998;77(1):8-19.

6. Markström A, Sundell K, Lysdahl M, Andersson G, Schedin U, Klang B. Quality-of-life evaluation of patients with neuromuscular and skeletal diseases treated with noninvasive and invasive home mechanical ventilation. Chest 2002;122(5):1695-1700.

7. Brurberg K, Landmark B, Kirkehei I, Reinar LM. Effect on longterm mechanical ventilation. 2012;14:1-91. Oslo: Nasjonalt kunnskapssenter for Helsetjenesten.

8. Stuart M, Michael Weinrich M. Home- and community-based longterm care: Lessons from Denmark. Gerontologist 2001;41(4):474480.

9. Rabec C, Rodenstein D, Leger P, Rouault S, Perrin C, GonzalezBermejo J, SomnoNIV group. Ventilator modes and settings during non-invasive ventilation: effects on respiratory events and implications for their identification. Thorax 2011;66(2):170-178.

10. Theerakittikul T, Ricaurte B, Aboussouan LS. Noninvasive positive pressure ventilation for stable outpatients: CPAP and beyond. Cleve Clin J Med 2010;77(10):705-714.

11. Lloyd-Owen SJ, Donaldson GC, Ambrosino N, Escarabill J, Farre R, Robert D, et al. Patterns of home mechanical ventilation use in europe: results from the Eurovent survey. Eur Respir J 2005;25(6): $1025-1031$

12. Løvschall C, Küchen S, Sprehn M, Nørregaard O, Carstensen K, Ørtenblad L, et al. Health Technology Assessment of Home Mechanical Ventilation. DEFACTUM, Central Denmark Region. 2017.

13. Lofaso F, Prigent H, Tiffreau V, Menoury N, Toussaint M, Monnier AF, et al.; Association Française Contre les Myopathies research group. Long-term mechanical ventilation equipment for neuromus- cular patients: meeting the expectations of patients and prescribers. Respir Care 2014;59(1):97-106.

14. Ballangrud R, Bogsti WB, Johansson IS. Clients' experiences of living at home with a mechanical ventilator. J Adv Nurs 2009;65(2): 425-434.

15. Lindahl B, Sandman PO, Rasmussen BH. On being dependent on home mechanical ventilation: depictions of patients' experiences over time. Qual Health Res 2006;16(7):881-901.

16. Thomas J, Harden A. Methods for the thematic synthesis of qualitative research in systematic reviews. BMC Med Res Methodol 2008; $8: 8-45$.

17. Lewin S, Glenton C, Munthe-Kaas H, Carlsen B, Colvin CJ, Gülmezoglu M, et al. Using qualitative evidence in decision making for health and social interventions: an approach to assess confidence in findings from qualitative evidence syntheses (GRADE-CERQual). PLoS Med 2015;12(10):e1001895.

18. Lewin S, Bohren M, Rashidian A, Munthe-Kaas H, Glenton C, Colvin $\mathrm{CJ}$, et al. Applying GRADE-CERQual to qualitative evidence synthesis findings - paper 2: how to make an overall CERQual assessment of confidence and create a summary of qualitative findings table. Implement Sci 2018;13(Suppl 1):10.

19. Lindahl B. Patients' suggestions about how to make life at home easier when dependent on ventilator treatment-a secondary analysis. Scand J Caring Sci 2010;24(4):684-692.

20. Briscoe WP, Woodgate RL. Sustaining self: the lived experience of transition to long-term ventilation. Qual Health Res 2010;20(1):57-67.

21. Sundling I, Ekman S, Weinberg J, Klefbeck B. Patients' with ALS and caregivers' experiences of non-invasive home ventilation. Adv Physiother 2009;11(3):114-120.

22. Dreyer PS, Steffensen BF, Pedersen BD. Life with home mechanical ventilation for young men with Duchenne muscular dystrophy. J Adv Nurs 2010;66(4):753-762.

23. Kelly CA, Lynes D, O'Brien MR, Shaw B. A wolf in sheep's clothing? patients' and healthcare professionals' perceptions of oxygen therapy: an interpretative phenomenological analysis. Clin Respir J 2018;12(2):616-632.

24. Nakarada-Kordic I, Patterson N, Wrapson J, Reay SD. A systematic review of patient and caregiver experiences with a tracheostomy. Patient 2018;11(2):175-191.

25. Ørtenblad L, Meillier L, Jønsson AR. Multi-morbidity: a patient perspective on navigating the health care system and everyday life. Chronic Illn 2018;14(4):271-282.

26. Ando H, Williams C, Angus RM, Thornton EW, Chakrabarti B, Cousins R, et al. Why don't they accept non-invasive ventilation? Insight into the interpersonal perspectives of patients with motor neurone disease. Br J Health Psychol 2015;20(2):341-359.

27. Liberati A, Altman DG, Tetzlaff J, Mulrow C, Gøtzsche PC, Ioannidis JPA, et al. The PRISMA Statement for Reporting Systematic Reviews and Meta-Analyses of Studies That Evaluate Health Care Interventions: Explanation and Elaboration. PLOS Medicine 2009; 6(7):e1000100. 